RASĀYAN J. Chem.

Vol. 13 | No. 4 |2274-2280| October - December | 2020 ISSN: 0974-1496 | e-ISSN: 0976-0083 | CODEN: RJCABP

\title{
DEGRADATION OF CIPROFLOXACIN USING FENTON PROCESS AND ITS EFFECT ON BIODEGRADABILITY
}

\author{
V. K. Jyothirmai, S. Mary Rebekah Sharmila and Sija Arun* \\ Department of Civil Engineering, College of Engineering and Technology, SRM Institute of \\ Science and Technology, Kattankulathur, 603203, Chengalpattu District, Tamilnadu, India \\ *E-mail: sijaarun08@gmail.com
}

\begin{abstract}
Ciprofloxacin (CIP) is a second-generation fluoroquinolone antibiotic used for the prevention and treatment of infections in humans as well as in animals. As an emerging contaminant in the environment, its main source is the pharmaceutical industry and municipal wastewater treatment plants. The contaminant surpasses the conventional treatment process and end up in surface water bodies and cause toxic to aquatic organisms and generate antibiotic resistance. Hence, the degradation of CIP and its effect on biodegradability using an advanced oxidation process such as the Fenton process was investigated in the present study. A maximum of $71 \%$ removal of CIP was achieved from an aqueous solution of CIP with $10 \mathrm{mg} / \mathrm{L}$ of initial concentration at 60 min with an optimum concentration of Fe (II) $/ \mathrm{H}_{2} \mathrm{O}_{2}$ ratio of $1: 10$ at $\mathrm{pH}=3$. Chemical Oxygen Demand (COD) and Biological Oxygen Demand (BOD) were determined to find the biodegradability of the aqueous solution during the treatment process. The process enhanced the biodegradability of the solution with a considerable reduction in COD and an increase in BOD values.

Keywords: Ciprofloxacin, Fenton Process, Biodegradability, Degradation
\end{abstract}

(C) RASĀYAN. All rights reserved

\section{INTRODUCTION}

Pharmaceutical industries are outspreading their roots from the mid-1800s through inventions and applied research work. Pharmaceutical compounds consist of a vast community of human and veterinary medicinal compounds that are being used globally for a long time. ${ }^{1,2}$ These compounds are designed to interfere with human and animal hormone systems as a cure to human health at nano concentration levels and therefore as a key property, they are designed to persistent against biological degradation. Pharmaceuticals enter the environment in several ways (i) from the excretion of humans and animals via urine and fecal products (ii) from industrial effluents, disposals from hospitals, and agricultural runoff. In sewage treatment plants, pharmaceuticals are still not eliminated and are instead discharged into receiving water systems. Thus the prevalence of these pollutants in surface water and subsurface waters that are organic and inorganic by nature have resulted from sewage treatment plants, polluted soils, farm runoff, industrial wastewaters, and storage leakage. Many organic compounds are known as harmful and hazardous even if they are detected at very low doses. ${ }^{3}$ With the development in measuring technologies, the pharmaceuticals are being detected and identified even in trace level concentrations. The quantity of these drugs in the environment is minimal, but their continued persistence in the environment can pose a significant long-term risk. Therefore, in recent years these are considered an emerging environmental problem. ${ }^{4}$

Antibiotics are a group of pharmaceutical compounds used as human and veterinary medicines to treat bacterial infections. Out of these, ciprofloxacin (CIP) is a commonly used antibiotic and its production and use are very high in a country like India. ${ }^{5}$ After production and use, the effluents from industries and sewage treatment plants have to be treated properly to remove this contaminant. ${ }^{6}$ The compound by its origin, selfretain their chemical structure and are non-biodegradable, so its existence in the environment for a longer period is considered to be a threat for life. ${ }^{5}$ The existence of such chemically resistant compounds in water creates a major threat to public health because they are poisonous, damage endocrine system, mutagenic, or possibly carcinogenic ${ }^{3}$. While the concentration of such pharmaceutical compounds is very less in the aquatic environment, their constant presence may create a possible long-term danger to aquatic and terrestrial species. ${ }^{1}$

Rasayan J. Chem., 13(4), 2274-2280(2020)

http://dx.doi.org/10.31788/ RJC.2020.1346074

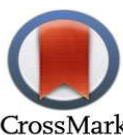


RASĀYAN J. Chem.

Vol. 13 | No. 4 |2274-2280| October - December | 2020

The complex structure of CIP cannot be removed by the biological treatment process and therefore require an advanced oxidation process (AOP) for its degradation. These special treatment methods employ chemical processes involving Fenton's based oxidation, UV irradiation, photolysis, photochemical treatment, electrochemical treatment, sonolysis, photocatalysis, etc. In these processes, hydroxyl radicals are generated via the removal reactions. ${ }^{7}$ AOPs can be used either individually or in collaboration with certain traditional procedures of treatment, based on the characteristics of the wastewater to be treated and the quality of the effluent required. For example, AOPs can be carried out as a pre-treatment step to transform bio recalcitrant compounds to intermediates that are more readily biodegradable, accompanied by conventional methods of treatment. ${ }^{1}$

In this present study, advanced oxidation using Fenton's reagent was used for the degradation of CIP. This method involves Fenton's reagent which constitutes ferrous ions and hydrogen peroxide and $\mathrm{Fe}^{2+}$ act as a catalyst to degrade or treat higher molecular structures to simple organic compounds. Formation of hydroxyl radicals and ionization of ferrous ion from $\mathrm{Fe}^{2+}$ state to $\mathrm{Fe}^{3+}$ act as coagulants and thereby both oxidation and coagulation occur in this method of treatment. Fenton reaction occurs according to the equation-

$$
\mathrm{Fe}^{2+}+\mathrm{H}_{2} \mathrm{O}_{2} \rightarrow \mathrm{Fe}^{3+}+\mathrm{OH}^{-}+\mathrm{OH}^{\bullet}
$$

There is proof that the reaction involved in the Fenton reaction is much more complex than that described in the equation ${ }^{7}$. The reaction is expected to complete in a short time for the Fenton procedure, depending on the concentration of $\mathrm{H}_{2} \mathrm{O}_{2}$ and $\mathrm{Fe}^{2+}$. The absolute destruction of COD occurs in a time interval of 5 minutes in comparison to the initial COD. Hydroxyl radicals typically target all compounds, including hydrogen peroxide, in wastewater. ${ }^{7}$ The production and operating costs for implementation of the reactor using Fenton's reagent are considered to be lower relative to the other AOP's. ${ }^{4}$ Degradation of CIP with Fenton's reagent can be easily adopted in treatment plants since both the reagents are cheap, ecofriendly, and easily available. So, the present study aims to find (i) the degradation rate of CIP from an aqueous solution using Fenton's reagent (ii) Factors affecting degradation (iii) the rate of change of biodegradability of CIP during Fenton's process.

\section{EXPERIMENTAL}

\section{Material and Methods}

The analytical grade Ciprofloxacin (99.9\% purity) was acquired from Sigma-Aldrich, and $10 \mathrm{ppm}$ solution was made by using a buffer solution. The buffer solution was prepared with $4 \%$ Sodium Hydroxide and analytical grade methanol. $\mathrm{FeSO}_{4} 7 \mathrm{H}_{2} \mathrm{O}$ (Ferrous sulfate heptahydrate) and Hydrogen peroxide $\left(30 \% \mathrm{H}_{2} \mathrm{O}_{2}\right)$ were purchased from SIS, Chennai. Sodium Hydroxide $(\mathrm{NaOH})$ and Sulphuric acid $\left(\mathrm{H}_{2} \mathrm{SO}_{4}\right)$ were used to adjust $\mathrm{pH}$. Syringe filters of $0.45 \mu \mathrm{m}$ size were used to remove the impurities from the sample before spectrophotometer analysis. The analysis was done in UV-VIS spectrophotometer, (Shimadzu UV 3600 Plus) at Nano Technology Research Center, SRM Institute of Science and Technology, Chennai.

\section{Experimental Procedure for Fenton reactions}

The absorption spectrum of CIP was plotted within the wavelength range of 100 to $700 \mathrm{~nm}$. The maximum absorbance was obtained at $262 \mathrm{~nm}$. The calibration curve was plotted with absorbance and different concentrations of CIP (2ppm, 4ppm, 6ppm, 8ppm, and 10ppm. This curve was used to find the concentration of CIP after each experiment.

For further experiments, the initial concentration of CIP was taken as $10 \mathrm{ppm}$. All the experiments were conducted in a $500 \mathrm{ml}$ glass beaker confined to a reactor volume of $200 \mathrm{ml}$ on a magnetic stirrer as an external energy source for thorough mixing with a running speed of 250-300 rpm. The initial experiments were conducted to find the optimum ratio of $\mathrm{Fe}^{2+}$ to $\mathrm{H}_{2} \mathrm{O}_{2}$ and optimum time for maximum degradation of CIP. The ratio of $\mathrm{Fe}^{2+}$ to $\mathrm{H}_{2} \mathrm{O}_{2}$ was varied from 1:5 to 1:20. The $\mathrm{pH}$ was adjusted to 3 and experiments were conducted at room temperature. A sample volume of $5 \mathrm{ml}$ was extracted at different time intervals and was passed through a $0.45 \mu \mathrm{m}$ syringe filter for analysis in the UV-VIS spectrophotometer. Further experiments were done to find the effect of $\mathrm{pH}$ and initial $\mathrm{Fe}^{2+}$ concentration. 
RASĀYAN J. Chem.

Vol. 13 | No. 4 |2274-2280| October - December | 2020

\section{Experimental Procedure for Biodegradability Test}

COD and BOD were determined in the laboratory by using APHA method numbers 5220D and 5210D respectively. The COD was determined by the closed reflux colorimetric test. The required samples were pipetted into the reagent solution and it was refluxed in the COD digester for 2 hours at $150^{\circ} \mathrm{C}$. COD was measured by using the Lovibond Spectrodirect instrument calorimetrically. $\mathrm{BOD}_{5}$ was measured using $\mathrm{BD}$ 600 Lovibond BOD analyzer. The required amount of two reagents-nitrification inhibitor and hydrogen peroxide solutions were added to the sample in BOD bottles and incubated for 5 days. The BOD was automatically read from the analyzer after 5 days.

\section{RESULTS AND DISCUSSION}

Degradation of CIP using Fenton's reagents was studied for various ratios of $\mathrm{Fe}^{2+} / \mathrm{H}_{2} \mathrm{O}_{2}$. The study was conducted to find the effect of various factors on the oxidation process. To find out the effect of Fenton oxidation on biodegradability, BOD, and COD of the solution were tested at different stages. The results of each experiment are discussed in further sections.

\section{Optimum Ratio of $\mathrm{Fe}^{2+}$ and $\mathrm{H}_{2} \mathrm{O}_{2}$ For Degradation of Ciprofloxacin}

Fenton's reagent is a combination of $\mathrm{Fe}^{2+}$ and $\mathrm{H}_{2} \mathrm{O}_{2}$. The rate of reaction varies with the concentration of these two reagents. So, it is very important to find out the combination of these two reagents which give the maximum degradation of CIP. The experiment was conducted at different ratios of $\mathrm{Fe}^{2+} / \mathrm{H}_{2} \mathrm{O}_{2}$ and the degradation of CIP was found out at various reaction times. The initial concentration of CIP was $10 \mathrm{ppm}$ and the $\mathrm{pH}$ of the solution was adjusted with 3 molar $\mathrm{H}_{2} \mathrm{SO}_{4}$ and $\mathrm{NaOH}$ and maintained at 3 . In a reactor volume of $200 \mathrm{ml}$ of CIP, the required quantity of $\mathrm{Fe}^{2+}$ was added and mixed thoroughly on a magnetic stirrer. The reaction time starts when $\mathrm{H}_{2} \mathrm{O}_{2}$ was added to the solution. From a continuously mixed reactor, $5 \mathrm{ml}$ of the sample was extracted at different time intervals such as 5, 15, 30, 45, 60, 90, and 120 minutes. Immediately after extraction, the sample was passed through a $0.45 \mu \mathrm{m}$ syringe filter to remove all the impurities. The experiment was repeated for different ratios of $\mathrm{Fe}^{2+} / \mathrm{H}_{2} \mathrm{O}_{2}$ such as 1:5, 1:10, 1:15, and 1:20. The results of the experiments are shown in Fig.-1. It was observed that $30 \%$ of degradation happened in the first 5 minutes of reaction time. After that, the reaction was slow until it reaches an equilibrium state. This is because the production of $\mathrm{OH}^{*}$ radical is faster at the initial stage. ${ }^{8}$ Degradation of CIP increased with an increase in $\mathrm{Fe}^{2+} / \mathrm{H}_{2} \mathrm{O}_{2}$ ratio and a further increase in ratio reduced the degradation. The maximum degradation was obtained at 1:10 ratio with a removal efficiency of $71 \%$ and further for higher ratios the degradation of CIP was reduced. The decrease in degradation with a higher ratio can be explained by two reasons. (i) With the increase in the ratio of $\mathrm{Fe}^{2+} / \mathrm{H}_{2} \mathrm{O}_{2}, \mathrm{Fe}^{2+}$ is converted into $\mathrm{Fe}^{3+}$ at an excess concentration of $\mathrm{H}_{2} \mathrm{O}_{2}$ concerning $\mathrm{Fe}^{2+}$ concentration ${ }^{9}$. This is explained the equation (2).

$$
\mathrm{Fe}^{2+}+\mathrm{OH}^{\cdot} \longrightarrow \mathrm{Fe}^{3+}+\mathrm{OH}^{-}
$$

(ii) $\mathrm{OH}^{\cdot}$ radical is scavenged by $\mathrm{H}^{+}$and $\mathrm{OH}^{-}$ions and this is explained by the following equation $(3)^{9}$ and (4). ${ }^{10}$

$$
\begin{aligned}
& \mathrm{OH}^{\cdot}+\mathrm{OH}^{-} \longrightarrow \mathrm{H}_{2} \mathrm{O}+\mathrm{O}^{-} \\
& \mathrm{OH}^{\cdot}+\mathrm{H}^{+}+\mathrm{e} \longrightarrow \mathrm{H}_{2} \mathrm{O}
\end{aligned}
$$

The maximum degradation was observed at 60 minutes for all the ratios and after that degradation was minimum indicating that the equilibrium state was achieved at 60 minutes. The same was reported for all the ratios, the degradation of CIP was $35 \%, 52 \%$, and $50 \%$ for $1: 5,1: 15$, and $1: 20$ ratios respectively. This shows that for low ratios the degradation was less and again for higher ratios the degradation was decreased. So it is evident from this experiment that the optimum ratio is $1: 10$. The same results were reported in most of the studies conducted for the removal of CIP by using Fenton's reagent as well as for other antibiotic compounds. In similar studies conducted by Fenton's reagents such as Giri et al, Guptha et al, Sun et al, and Yang et al achieved a maximum degradation of CIP as $74.4 \%, 70 \%, 77 \%$, and $56.8 \%$ respectively. The relationship between time and degradation is also almost the same when compared with other studies. Shah et al reported the maximum degradation at $80 \mathrm{~min}$. 
RASĀYAN J. Chem.

Vol. 13 | No. 4 |2274-2280| October - December | 2020

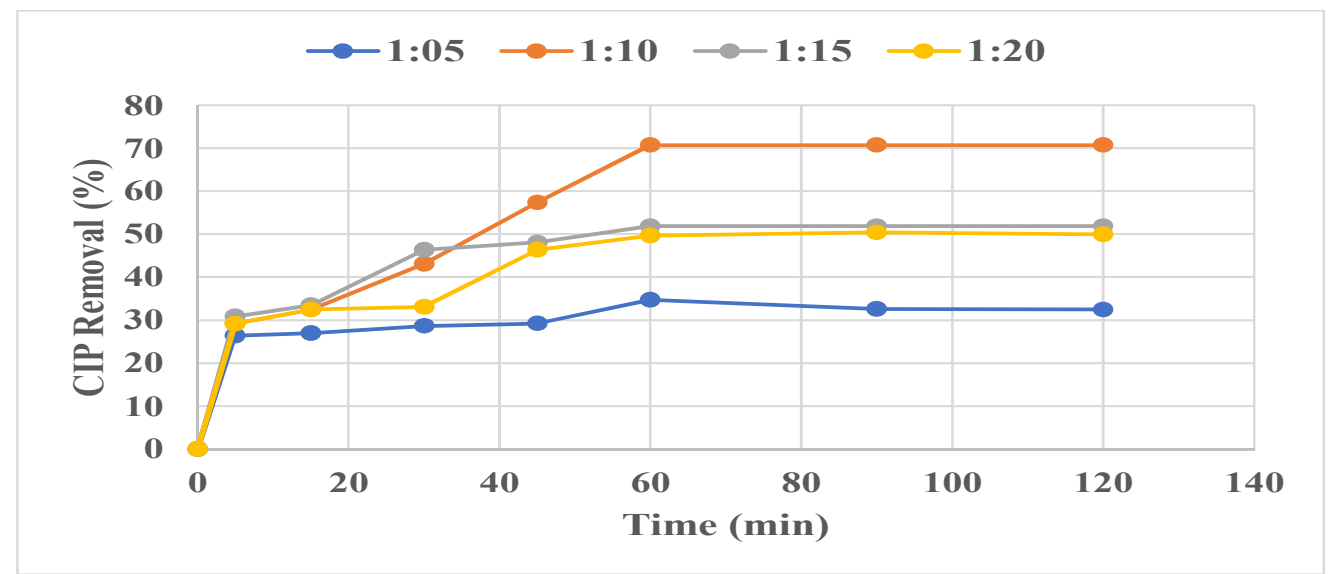

\section{Effect of pH on Degradation}

Fig.-1: Relation between $\mathrm{Fe}^{2+}: \mathrm{H}_{2} \mathrm{O}_{2}$ Ratio and Removal of Ciprofloxacin

Among the numerous desirable conditions influencing the reaction rate, $\mathrm{pH}$ is of great significance because $\mathrm{H}_{2} \mathrm{O}_{2}$ and $\mathrm{Fe}^{2+}$ generate hydrogen radical in acidic conditions. ${ }^{10} \mathrm{H}_{2} \mathrm{O}_{2}$ by definition is strongly oxidative, $\mathrm{Fe}^{+}$used in the reaction functions as a catalyst, and the $\mathrm{pH}$ of the solution assists in the reaction kinetics. ${ }^{10}$ From the previous experiment ratio of $\mathrm{Fe}^{2+} / \mathrm{H}_{2} \mathrm{O}_{2}$ and time of maximum degradation was optimized as 1:10 and $60 \mathrm{~min}$ respectively. These two values were kept constant to find the effect of $\mathrm{pH}$ on the reaction rate. The $\mathrm{pH}$ was varied from 2 to 4 and the degradation of CIP was found out. The variation of CIP removal percentage with $\mathrm{pH}$ is shown in Fig.-2. From the experiment, it is found that the maximum removal occurred at $\mathrm{pH}=3$.

The initial $\mathrm{pH}$ of the aqueous $10 \mathrm{ppm}$ CIP solution is 8 . The $\mathrm{pH}$ of the solution was reduced by adding $3 \mathrm{M}$ Sulphuric Acid. No major variations in treatment effects were found when assessed with an initial higher $\mathrm{pH}$ level greater than 4.5 , while $\mathrm{pH} 3.0$ produced marginally better outcomes. This result is compatible with recent works and results indicate that the ideal $\mathrm{pH}$ for oxidation by Fenton's reagent does not depend on the composition of the wastewater but depends on $\mathrm{pH}$ in the range of 3-5. ${ }^{11}$ It's very well accepted that the $\mathrm{H}_{2} \mathrm{O}_{2}+\mathrm{Fe}^{2+}$ reaction will produce radical hydrogen in an acidic environment. ${ }^{10}$ Ferrous ions are considered to be not stable at $\mathrm{pH}>4.0$, simple to form ferric ions, and tend to create complexes of ferric hydroxides or ferric oxyhydroxides which do not react with hydrogen peroxide due to its low activity. ${ }^{12}$ At high $\mathrm{pH}$, hydrogen peroxide becomes unstable and decomposes to $\mathrm{H}_{2} \mathrm{O}$ and $\mathrm{O}_{2} .{ }^{10}$ Shah et al ${ }^{13}$ also reported that the maximum degradation of CIP was achieved at $\mathrm{pH}=2.5$ in $80 \mathrm{~min}$. The formation of ferrous and ferric hydroxide complexes at $\mathrm{pH} 6.0$ which had a much lower catalytic capacity than $\mathrm{Fe}^{2+}$ and resulted in the generation of a smaller amount of $\mathrm{OH}$ radical. ${ }^{14}$ This leads to less removal efficiency at higher $\mathrm{pH}$. The optimal $\mathrm{pH}$ value for the removal of various antibiotics such as amoxicillin ${ }^{15}$, is 3 and ampicillin at $\mathrm{pH}$ 3.7. ${ }^{16}$

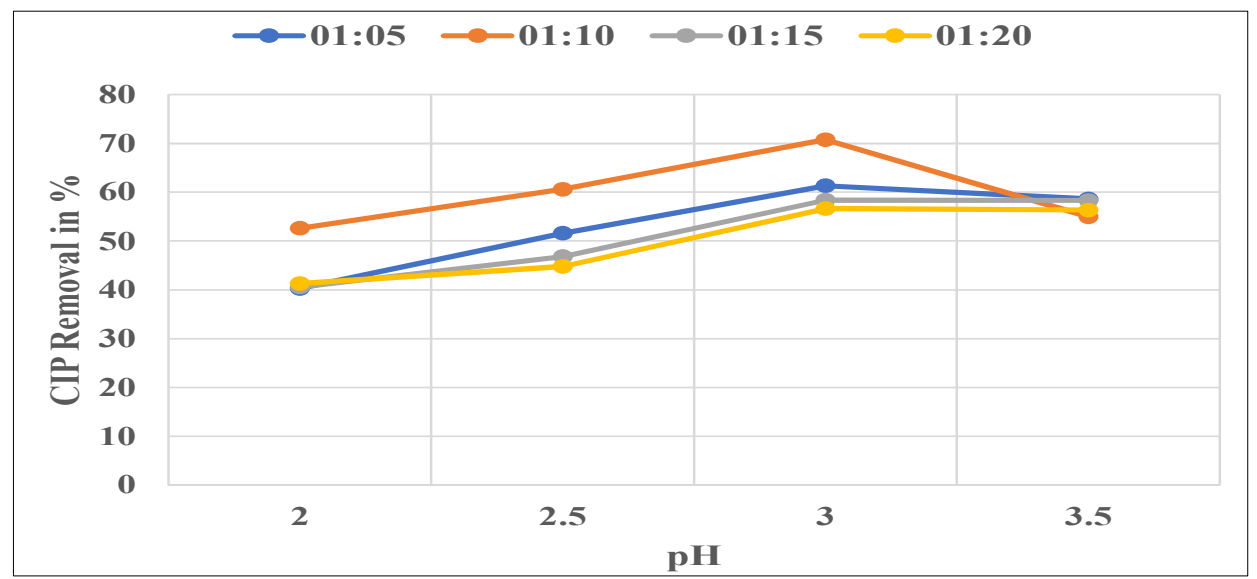

Fig.-2: Relation between $\mathrm{pH}$ and Removal of Ciprofloxacin 
RASĀYAN J. Chem.

Vol. 13 | No. 4 |2274-2280| October - December | 2020

\section{Effect of The Initial Concentration of $\mathrm{Fe}^{2+}$ on Degradation}

Among various factors that affect the efficiency of treatment, the concentration of $\mathrm{Fe}^{+}$is of prime importance. Ferric ions play a vital role as a catalyst in the process, which activates hydrogen peroxide for the production of hydroxyl radicals. An increase in the concentration of ferric ions can cause some degree boost in the development of hydroxyl radicals by hydrogen peroxide. ${ }^{10}$ In order to determine the optimum $\mathrm{Fe}^{2+}$, the experiment was conducted by varying concentration of $\mathrm{Fe}^{2+}$ such as $10 \mathrm{mg} / \mathrm{L}, 20 \mathrm{mg} / \mathrm{L}, 30 \mathrm{mg} / \mathrm{L}$ and $40 \mathrm{mg} / \mathrm{L}$. The treatment was conducted for a total of 60 minutes handling $200 \mathrm{ml}$ volume in a reactor by keeping all other parameters constant. The relation between $\mathrm{Fe}^{2+}$ concentration and degradation of CIP is shown in Fig.-3. The maximum removal was obtained at $30 \mathrm{mg} / 1$ of $\mathrm{Fe}^{2+}$ concentration and a further increase of $\mathrm{Fe}^{2+}$ reduces the degradation. Similar results were reported in various studies also. ${ }^{10,17}$ It means that the excess amount of $\mathrm{Fe}^{2+}$ as a scavenger reacts with hydroxyl radicals and form $\mathrm{Fe}^{3+}$ which has a negative impact on degradation as in eqn.-2. Kargi et al 2010 also reported the Amoxicillin removal by using Fenton's reagent showed that the maximum degradation was at $25 \mathrm{mg} / \mathrm{L}$ of $\mathrm{Fe}^{2+}$, after that there was a reduction in removal efficiency. A study on removal of CIP by electro-Fenton process also reported that an increase in $\mathrm{Fe}^{2+}$ concentration till $0.1 \mathrm{mM}$ increased the degradation, further increase reduced the degradation. ${ }^{18}$

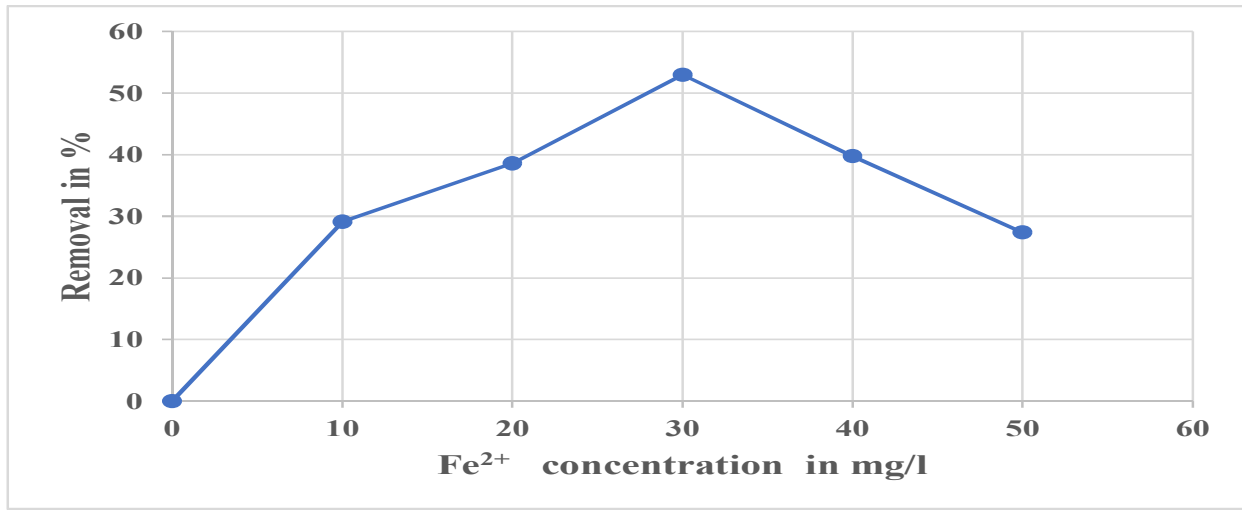

Fig.-3: Initial Concentration of $\mathrm{Fe}^{2+}$ and Its Effect on the Removal of Ciprofloxacin

\section{Effect of Fenton's Process on Biodegradability}

Most sewage treatment plants use the activated sludge process as their prime treatment method to remove organic materials from wastewater. But these biological processes do not completely remove pharmaceutical compounds such as CIP. The average removal efficiency of fluoroquinolones was approximately $65 \%$ during conventional wastewater treatment. ${ }^{19} \mathrm{CIP}$ is a chemical compound and it is not degraded by biological processes. Fenton's process improves the biodegradability of the solution, hence CIP can be removed by the biological process from the wastewater. The biodegradability of the solution can be determined from $\mathrm{BOD}_{5} / \mathrm{COD}$ ratio. If the $\mathrm{BOD}_{5} / \mathrm{COD}$ ratio is greater than 0.4 , the solution is biodegradable. Thus the overall efficiency of the treatment can be improved by a combined process such as Fenton's process coupled with a biological process. Fenton's process can be used as a pretreatment process that can be used to improve wastewater biodegradability. Hence the variation of biodegradability of the aqueous solution of CIP was determined during the oxidation process.

To evaluate the biodegradability, the $\mathrm{BOD}_{5} / \mathrm{COD}$ ratio was found out at different times of the degradation process. The solution is biodegradable when the $\mathrm{BOD}_{5} / \mathrm{COD}$ ratio greater than or equal to $0.4 .^{20}$ The initial $\mathrm{BOD}$ of the solution was zero indicates that the solution is non-biodegradable. The $\mathrm{BOD}_{5}$ and $\mathrm{COD}$ results are shown in Fig.-4. COD of the solution was considerably reduced during the Fenton process and BOD increased till 60 minutes after that there is a reduction in BOD. The maximum degradation of CIP was also achieved at 60 minutes. Gong et al $2015^{21}$ also reported, similar results in the degradation of levofloxacin using the electro Fenton process. Biodegradable intermediates were formed during the process and it enhances the $\mathrm{BOD}_{5}$ of the solution.Variation of $\mathrm{BOD}_{5} / \mathrm{COD}$ with time is shown in Fig.-5. At the starting of the experiment, $\mathrm{BOD}_{5} / \mathrm{COD}$ ratio was 0.04 which shows the non-biodegradability of the solution. The ratio 
RASĀYAN J. Chem.

Vol. 13 | No. 4 |2274-2280| October - December | 2020

further increased to 0.4 , indicating that the solution becomes biodegradable at 60 minutes and after that, there was a reduction in the ratio.

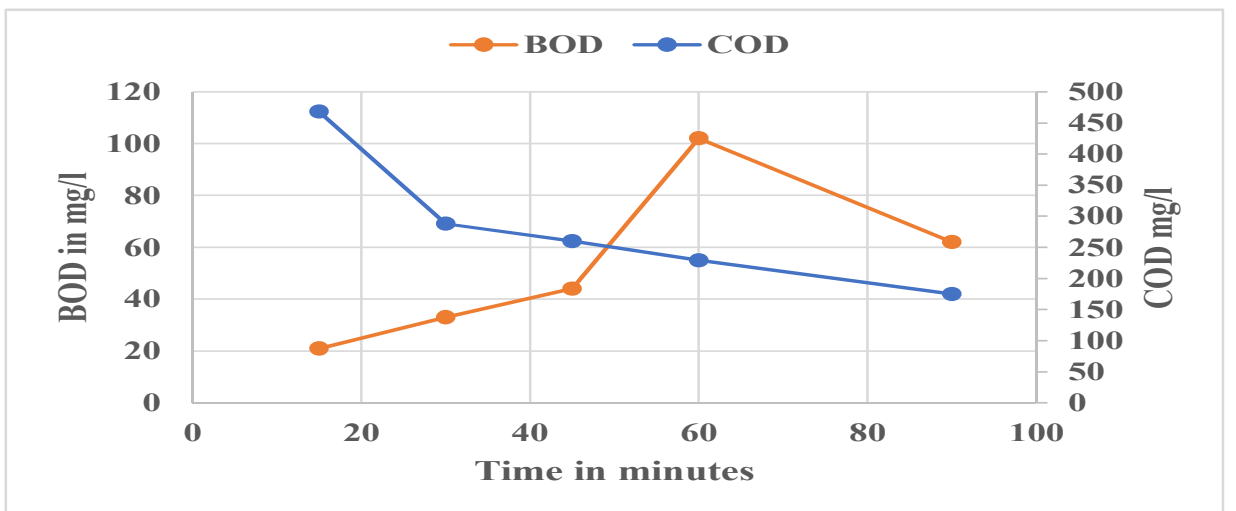

Fig.-4: $\mathrm{BOD}_{5}$ and COD Variations during Degradation of Ciprofloxacin using Fenton's Process

A study conducted on enoxacin degradation by the electro-Fenton process also reported that longer reaction time reduces biodegradability. ${ }^{22}$ It can be explained that the biodegradable intermediates formed in the initial stage of the process are easily removed by the hydroxyl radicals and hence there is a reduction in BOD. It can also be noted that the Fenton process transforms the structure of the pollutant into less toxic and make it biodegradable rather than mineralization. The results showed that 100 percent removal of pharmaceutical contaminants can be achieved when the Fenton process is used as a pretreatment method followed by a cheaper biological process in wastewater treatment plants.

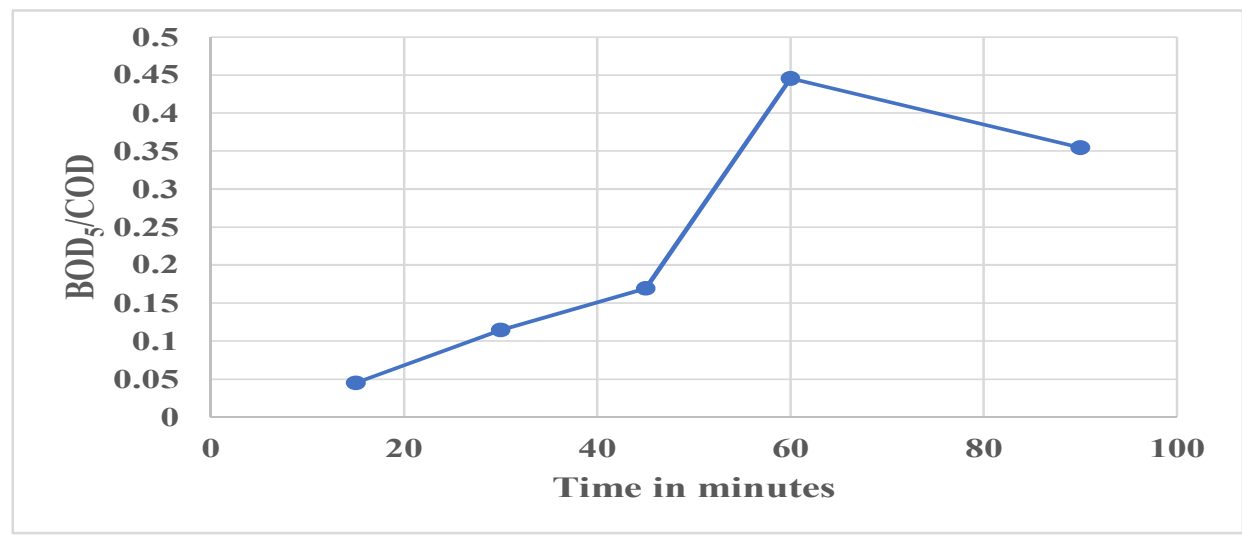

Fig. -5: Variation of $\mathrm{BOD}_{5} / \mathrm{COD}$ Ratio with Time

\section{CONCLUSION}

This experiment was conducted to address one of the cost-effective ways to remove ciprofloxacin antibiotics which are contaminating the various water sources since treatment plants are not effective in removing ciprofloxacin antibiotic specifically. From the above work, it can be concluded that:

- The operating parameters which affect the degradation of CIP are $\mathrm{pH}, \mathrm{Fe}^{2+}$ concentration, $\mathrm{H}_{2} \mathrm{O}_{2}$ concentration, and the ratio of $\mathrm{Fe}^{2+} / \mathrm{H}_{2} \mathrm{O}_{2}$.

- The optimum ratio of $\mathrm{Fe}^{2+} / \mathrm{H}_{2} \mathrm{O}_{2}$ for the maximum degradation of CIP was 1:10. The maximum degradation was also achieved at 60 minutes of reaction time at a $\mathrm{pH}$ value of 3 .

- $71 \%$ percentage of degradation of ciprofloxacin was achieved under optimum conditions.

- There was a considerable reduction in COD and an increase in BOD values which shows that the biodegradability of the solution was increased during the process. The solution becomes biodegradable and suitable for the biological process. This treatment process is suitable for wastewater with high COD content. 
- Fenton process can be used as a pretreatment method in treating industrial wastewater coupled with the biological process so that the organic contaminant level in the effluent can be effectively reduced thus natural resources can be protected from pollution with emerging contaminants.

\section{ACKNOWLEDGEMENT}

The authors express their sincere gratitude to the SRM Institute of Science and Technology for providing the lab facilities to conduct the experiment.

\section{REFERENCES}

1. M. Klavarioti , D. Mantzavinos , D. Kassinos , Environment International, 35(2), 402(2009), DOI: 10.1016/j.envint.2008.07.009

2. S.Arun, S.Krithiga, P. Chakraborty, Rasayan Journal of Chemistry, 12(2), 915(2019), DOI: $10.31788 /$ RJC.2019.1225161

3. A. Babuponnusami, K. Muthukumar, Journal of Environmental Chemical Engineering, 2(1), 557(2014), DOI:10.1016/j.jece.2013.10.011

4. M. I. Badawy, R. A. Wahaab, A.S. El-Kalliny, Journal of hazardous materials, 167, 567(2009), DOI: 10.1016/j.jhazmat.2009.01.023

5. A. Kotwani, K.Holloway, BMC infectious diseases, 11(1), 99(2011), DOI:10.1186/1471-2334-11-99

6. R.K. Chawla, S. Panda, K. Umasankar, S.P. Panda, D. Damayanthi, Rasayan Journal of Chemistry, 13(2), 1187(2020), DOI:10.31788/RJC.2020.1325079

7. C. Hofl, G. Sigl, O. Specht, IIse Wurdack, D. Wabner, Water Science and Technology, 35(4), 257(1997), DOI:10.1016/S0273-1223(97)00033-4

8. A.S. Giri, A.K. Golder, Recent Research in Science and Technology, 6(1), 6738(2014), DOI: $10.1039 / \mathrm{c} 3 \mathrm{ra} 45709 \mathrm{e}$

9. A.Gupta, A. Garg, Chemosphere, 193, 1181(2018), DOI:10.1016/j.chemosphere.2017.11.046

10. J.F. Yang, H.H. Chen, Advanced Materials Research, 610, 352(2013), DOI: 10.4028/www.scientific.net/AMR.610-613.352

11. H. Tekin, O. Bilkay, S.S. Ataberk, T.H. Balta, I.H. Ceribasi, F.D. Sanin, F.B. Dilek, U. Yetis, Journal of Hazardous Materials, 136(2), 258(2006), DOI:10.1016/j.jhazmat.2005.12.012

12. S. Wang, Dyes and Pigments, 76(3), 714(2008), DOI:10.1016/j.dyepig.2007.01.012

13. N.S. Shah, A.D.Rizwan, J.A. Khan, M. Sayed, Z.U. Khan, B. Murtaza , J. Iqbal , S.U. Din , M. Imran,M. Nadeem, H. Ala'a, Process Safety and Environmental Protection, 117, 473(2018), DOI: 10.1016/j.psep.2018.05.020

14. S.P. Sun, H.Q. Guo, Q. Ke, J.H. Sun, S.H. Shi, M.L. Zhang, Zhou, Environmental Engineering Science, 26(4), 753(2009), DOI:10.1089/ees.2008.0076

15. M. Verma, A.K. Haritash, Journal of Environmental Chemical Engineering. 7(1), 102886(2019), DOI: $10.1016 /$ j.jece.2019.102886

16. O. Rozas, D. Contreras, M.A. Mondaca, M. Pérez-Moya, H.D. Mansilla, Journal of Hazardous Materials, 177(1-3), 1025(2010), DOI:10.1016/j.jhazmat.2010.01.023

17. F. Ay, F. Kargi, Journal of Hazardous Materials, 179(1-3), 622(2010),DOI:10.1016/j.jhazmat.2010.03.048

18. M.S. Yahya, N. Oturan, K. El Kacemi, M. El Karbane, C.T. Aravindakumar, M.A. Oturan, Chemosphere, 117, 447(2014), DOI:10.1016/j.chemosphere.2014.08.016

19. K. He, A.D. Soares, H. Adejumo, M. McDiarmid, K. Squibb, L. Blaney, Journal of Pharmaceutical and Biomedical Analysis, 106, 136(2014), DOI:10.1016/j.jpba.2014.11.020

20. N.A. Salles, F. Fourcade, F. Geneste, D. Floner, A. Amrane, Journal of Hazardous Materials, 181(13), 617(2010), DOI: 10.1016/j.jhazmat.2010.05.057

21. Y. Gong, J. Li, Y. Zhang, M. Zhang, X. Tian, A. Wang, Journal of Hazardous Materials, 304, 320(2015), DOI:10.1016/j.jhazmat.2015.10.064

22. C. Annabi, F. Fourcade, I. Soutrel, F. Geneste, D. Floner, N. Bellakhal, A. Amrane, Journal of Environmental Management, 165, 96(2016), DOI:10.1016/j.jenvman.2015.09.018

[RJC-6074/2020] 